\title{
The Long-Term Effectiveness of Advertising Driven Sales for E-Commerce SMEs
}

\author{
Marta Christina SUCIU \\ Bucharest University of Economic Studies, Bucharest, Romania, \\ christina.suciu@economie.ase.ro \\ Christian NĂSULEA \\ University of Bucharest, Bucharest, Romania \\ christian@nasulea.ro \\ Diana Florentina NĂSULEA \\ Bucharest University of Economic Studies, Bucharest, Romania, \\ diana@nasulea.ro
}

PICBE |

\begin{abstract}
The digital transformation allowed for new business models to emerge. As e-commerce seems to be the future of retail, an increased number of entrepreneurs are trying to better leverage advertising in a way that leads to a sustainable business model on medium to long-term. Retail enterprises are spending huge amounts of money on search engine and social media paid advertising in order to make their products visible and thus, become more profitable. However, the academic literature suggests contradictory findings on the effectiveness of paid advertising. While it seems that for already established companies like e-Bay, shutting off paid campaigns doesn't proportionally decrease the website's traffic, for other large companies with more competitors the findings show the opposite, meaning that most of the traffic goes down when paid-campaigns are shut off. The aim of our paper is to assess the impact of paid campaigns on the long-term revenues of small and medium enterprises activating in e-commerce. Is investing in paid advertising at the beginning enough to build a business model that can sustain itself or does less advertising translate directly in less sales? We conduct a study for a number of Romanian e-commerce businesses in order to determine the effectiveness of paid advertising and its impact on the long-term revenue stream. Our findings contribute to the existing research through valuable data on small and medium size enterprises and can help business managers make more informed decisions when it comes to their paid advertising budget and strategy.
\end{abstract}

Keywords: online advertising, e-commerce, marketing, online sales.

\section{Introduction}

With the beginning of the digital era and the growth of social platforms and search engines, the possibilities for advertising have increased exponentially. Most companies have restructured their budget and approach to advertising in order to remain competitive and reach a global audience. Others have seized the opportunity and built online stores whose products are now sold on all continents due to the decreased start-up costs and increased possibilities of creating awareness. Advertising became a major focus for small, medium, and large companies across the world. In 2016, online advertising revenues in the USA alone have surpassed revenues coming from television marketing (PricewaterhouseCoopers, 2017). According to Statista (2019) global digital advertising spending is estimated to increase from $\$ 226.6$ billion in 2017 to $\$ 464.73$ billion in 2022 . 
Advertising conversions and the impact of advertising on sales have always been difficult to measure. If we think about traditional forms of advertising such as print, TV or radio, impact was almost impossible to determine without complex surveys to which consumers are generally not very open. All this has changed in the case of online advertising and its great variety of strategies and channels. If email marketing, using newsletters, used to be extremely well regarded by advertisers and companies some years ago (Hudák, Kianičková, \& Madleňák, 2017), over the past five years, search engines, social media platforms and display advertising have increased in popularity because they enabled the use of much more customizable ads with very specific target audiences. Since 2017, as video content has exploded both in terms of rate of creation and reach, we have also witnessed a lot of growth in the number of advertising affiliates and in the field of influencer marketing.

Regardless of their form, online advertising channels provide an exciting and promising environment for marketers because they allow for ad budgets to only be used on those consumers who can be converted into buyers. This is mainly due to two reasons. Firstly, with online advertising, targeting capabilities are virtually unlimited as it is possible for businesses to narrow down their audience to the granularity of a single individual who fits the intended buyer profile. Furthermore, online advertising allows for activity-related targeting (Goldfarb, 2014), meaning that, for instance, when selling sports equipment, the advertising can specifically target readers of sports magazines (Blake, Nosko, \& Tadelis, 2015), or even people interested in a particular branch associated to a particular sport. Secondly, advertisers can track data instantly and measure the effectiveness of their campaigns, while being able to adjust their ads and gain even more conversions.

While a lot of new business opportunities have also appeared, with the growth of online advertising, for small and medium enterprises this new approach was and continues to be a real challenge. Advertising in 2019 has transformed into a contest over who spends more. Cost per click is increasing and conversions are becoming difficult to achieve, while advertising budgets keep increasing. In this paper we explore two major issues. The first one is related to the impact of advertising budgets on creating reach. The aim here is to determine whether these costs are essential or not. The results can then be used to shape the framework for better marketing strategies for those who want to engage in e-commerce businesses. The second one refers to the long-term impact of advertising driven sales on e-commerce small and medium enterprises (SMEs). We aim to find out if paid advertising yields long term results, in the sense that it is possible in some cases that stopping advertising campaigns would still translate to sales. Our goal is to first determine how significant the impact of online advertising is on SME sales. Then we can look into how the challenges faced by SMEs can be overcome with smart strategies and budget planning. Lastly, we can assess if paid advertising can translate to increased revenues in the long run.

We therefore test the following hypotheses:

H1. In the short run, there is a strong correlation between advertising spending and the total number of visitors to a website

H2. Continuous advertising campaigns lead to increased organic sales in the long run. 


\section{Literature review}

Back in 2013 it was already considered essential by marketers for businesses to have a social media presence as part of their marketing strategy (eMarketer, 2013). The literature on social media advertising is extensive. The importance of social networks in achieving better ad effectiveness and customer engagement has been researched at length by Pooja et al. (2012), Tucker (2012) and (Taylor, Lewin, \& Strutton, 2011). Our paper builds, partly, on the existing research concerning online advertising models. Recent research conducted by Lee, Hosanagar, \& Nair (2018) has analysed the nature of 106316 Facebook messages and has concluded that purely informative ads have a lower conversion rate than content-sensible ads that adapt to personailty related attributes, like humour. Brettel, Reich, Gavilanes, \& Flatten (2015) have analyzed, using the approach of Vakratsas \& Ambler (1999) four types of advertising incentives on Facebook, looking at likes, impressions, page views and user contributions to determine the short and long-term impact on the sales of a major German ecommerce retailer. They have discovered that, despite their low short-term conversion, likes have a tendency to be the strongest sales drivers in the long run. Peng \& Van den Bulte (2016) have investigated the effectiveness of financial incentives given to paid endorsers for advertising. Buhalis \& Mamalakis (2015) have analysed the return on investment (ROI) of social media paid advertising using a Greek Hotel as a case study. Their results show that social media campaigns have both financial and non-financial results. The firsts sometimes come indirectly, as conversions for booking are harder to achieve through social media although Facebook's new functionalities allow for direct booking. Non financial results came in the form of growing the hotel's reputation and popularity. Their results confirm that, for certain industries, paid advertising can translate to long-term advantages.

In specialized literature search engine advertising refers to (De Corniere, 2016, p. 156):

the display of "sponsored links" on a search engine results page alongside "organic links." Whereas organic links are free, sponsored links are the main source of revenue for search engines. The standard pricing scheme in the industry is per click pricing: search engines collect fees from advertisers every time a consumer clicks on their link."

Regarding the cross-effectiveness of both social media and search engine advertising Yang \& Shan (2016) have analysed the influence of social media affiliation, conversation and responsiveness on search engine advertising effectiveness and conversion rates. Their results show that brand engagement on social media has a high degree of spillover onto search engine advertising efficiency. Aswani, Kar, Ilavarasan, \& Dwivedi (2018) looked at the potential disadvantages of search-engine advertising performed by freelancers and small enterprises. Their results show that problems such as transaction and coordination costs can affect the company's long term benefits in the case of failed Search Engine Marketing (SEM). Yang, Shi, \& Wang, (2015) have explored the relationship between SEM and e-commerce performance using the case study of China's B2C e-commerce enterprises. Their results show a positive correlation between SEM and firm performance. One of the most extensive experimental studies on paid search effectiveness was performed by Blake, Nosko, \& Tadelis (2015) and it explored SEM data for eBay, showing that brand keyword ads have almost zero 
benefits, while returns from paid search only represent a fraction of total sales for such a big company with an already loyal customer pool.

Considering the results of the previously mentioned research, and the success of our previous work on Romanian E-Commerce Retailers (Suciu et al. 2018), we have decided to focus on SMEs. Our paper explores the effectiveness of both social media marketing and search engine advertising on the long term ROI of 4 Romanian e-commerce SMEs.

PICBE |

\section{Methodology}

To measure the impact of paid advertising on sales we have analysed statistical data from a specialised Romanian Internet marketing agency. Our case study was initially based on quantitative Google Analytics and Facebook Advertising Insights data coming from 4 Romanian e-commerce SMEs between January 1 ${ }^{\text {st }}, 2017$ and December 31 ${ }^{\text {st }}, 2018$. The firms were selected based on the following criteria:

1) Industry - to be able to generalize and observe patterns over a series of fields we selected companies from the publishing, retail, food and home-improvement industries.

2) Size - as a control variable, we have selected four SMEs with a representative market share and profit in their respective industries. Additionally, 3 out of the 4 selected firms started operating between July 2016 and January 2017, while the fourth was established in 1993 and is equally well positioned in its respective market. This allowed us to determine if there is a correlation between the impact of advertising on sales and the age of the company.

3) Budget strategy - All four SMEs have decreased their advertising budget in 2018 due to a variety of reasons such as lower conversions, increased organic traffic or decreased profits.

Table 1. Selected Romanian SMEs Market Share

\begin{tabular}{|c|c|c|}
\hline Company & Industry & Estimated Market Share \\
\hline A & Publishing & $0.08 \%$ \\
\hline B & Retail & $0.01 \%$ \\
\hline C & Food & $0.02 \%$ \\
\hline D & Home-improvement & $0.03 \%$ \\
\hline
\end{tabular}

We decided to only focus on data from Facebook Advertising and Google AdWords as these were the most used advertising channels on the Romanian market for the period we examined. The compiled data refers to indicators measuring:

a) Costs - advertising budgets structured for either months and trimesters;

b) Average cost per click (CPC);

c) Reach - paid and organic reach;

d) Conversions - average conversion rate (CR);

e) Return on ad spending (RAS);

f) Return on investment (ROI);

g) Average value of shopping cart (VSC);

h) Number of repeat customers; and 
i) Average lifetime value (LTV).

Return on ad spending is an indicator meant to determine the outcome and value of the advertising campaign by computing how much profit was earned for every spent unit. For RAS we have used the following formula:

$$
\text { Return on ad spending }=\frac{\text { Profit from ad campaign }}{\text { Cost from ad campaign }}
$$

while for return on investment rate we have used the following formula:

$$
\text { Return on investment }=\frac{\text { Average profit }- \text { Advertising budget }}{\text { Advertising budget }}
$$

We have built on the model developed by Buhalis \& Mamalakis (2015) that argues for a different approach to ROI computations in marketing due to the complexity of the metrics. Hence, the non-financial measurements such as page views, comments and brand reach have a positive impact on the long-term conversions, meaning that some of the paid reach will eventually transform into organic traffic and sales. This means that computing ROI based only on profit coming from paid advertising would be flawed when it comes to online marketing, thus we consider it is better to include the total average profit since it is in fact largely affected by paid advertising especially in cases where conversions do not take place immediately (clothing, food etc).

The Average Lifetime Value (LTV) was used to measure how valuable the customers aquired through paid advertising are to the business based on lifetime performance.

We have also performed interviews with the marketing specialists of the four selected companies in order to better understand their choice of a) marketing channels and b) structuring of the advertising budgets for every trimester. This has proven extremely useful to our understanding of the SMEs business plan and marketing strategy.

At the request of some of the companies in our sample group, most results presented in this paper have been rounded up to the nearest integer.

\section{Results and discussions}

The four SMEs in our case study have a yearly advertising budget that ranges from $€ 5000$ to $€ 12500$. As shown in Fig. 1. the respective budgets have decreased in 2018 as compared to 2017 for all four of our SMEs. Company A has decreased its advertising budget by roughly $12 \%$, Company B by $13 \%$, Company C by $23 \%$, and Company D by $13 \%$. 


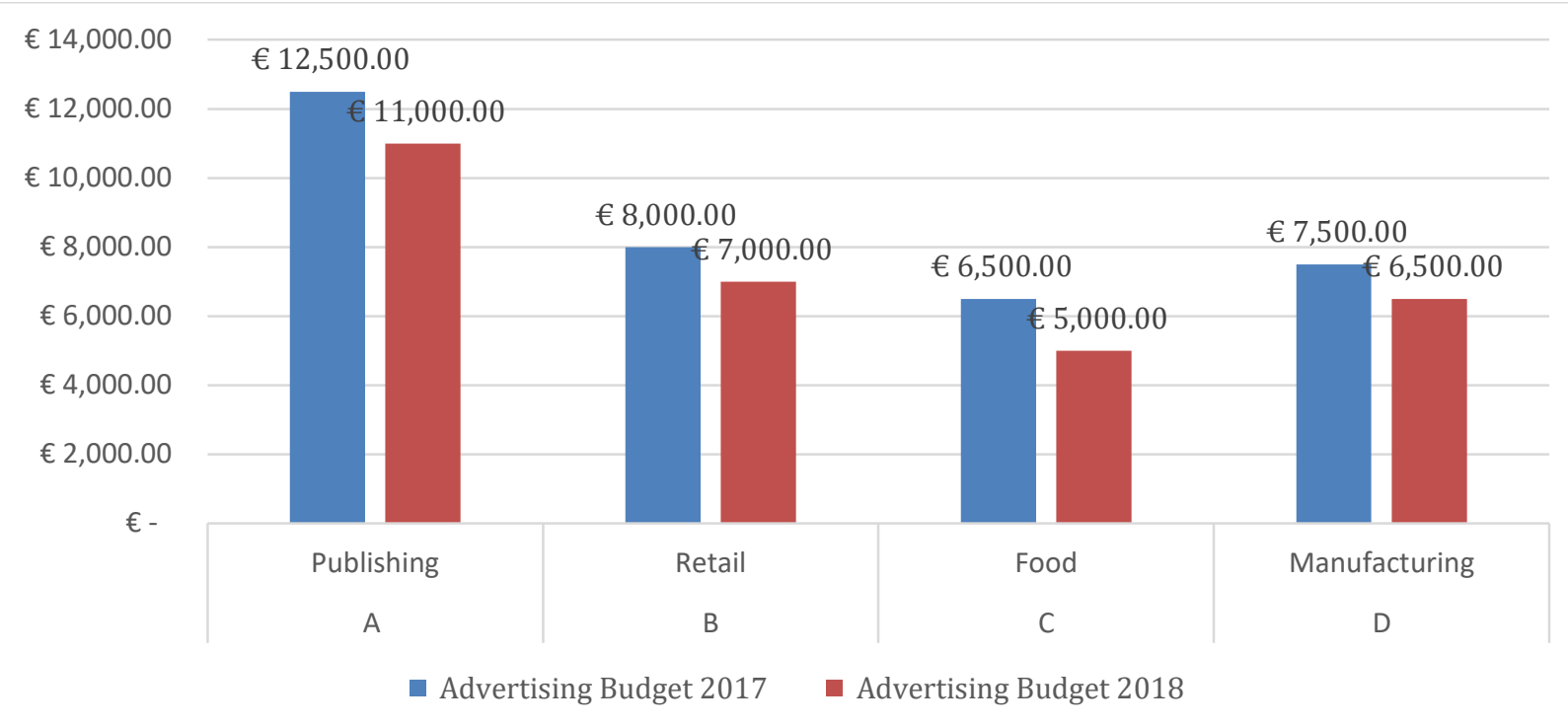

PICBE | 1185

Fig. 1. SMEs advertising budgets for 2017-2018

Source: Authors' own research

For the purpose of our analysis we have structured the advertising budgets of the companies based on trimesters rather than months, after gaining additional insights from our interviews with their marketing officers, as this would bring more relevance to our findings on the SMEs' marketing strategies. Table 2 shows the SMEs' advertising budgets. Company A, operating in the publishing industry, expends most of its advertising budget in the $4^{\text {th }}$ trimester partly due to the start of the school year in the fall, which increases the demand for textbooks and other educational resources, and partly due to shopping habits related to the winter holidays. During the summer the demand and advertising are at a minimum. A similar trend is followed by both company B operating in the retail sector, with most products being associated with the fashion industry, and D - home-improvement, due to the increased competition and demand during Black Friday and the winter holidays. The rest of the budget is quite evenly split throughout the year. For company $\mathrm{C}$, operating in the food industry (food delivery), we see an increase in the advertising budget for the $3^{\text {rd }}$ trimester due to holidays, seasonal tourism, and variations in pedestrian traffic in the geographical area serviced by the company.

Table.2 Structure of SMEs advertising budget for 2017-2018

\begin{tabular}{|c|c|c|c|c|c|c|c|c|}
\hline \multirow{2}{*}{ Company } & \multicolumn{2}{|c|}{ 1st trimester } & \multicolumn{2}{c|}{ 2nd trimester } & \multicolumn{2}{c|}{ 3rd trimester } & \multicolumn{2}{c|}{ 4th trimester } \\
\cline { 2 - 9 } & $\mathbf{2 0 1 7}$ & $\mathbf{2 0 1 8}$ & $\mathbf{2 0 1 7}$ & $\mathbf{2 0 1 8}$ & $\mathbf{2 0 1 7}$ & $\mathbf{2 0 1 8}$ & $\mathbf{2 0 1 7}$ & $\mathbf{2 0 1 8}$ \\
\hline A & $27 \%$ & $27 \%$ & $19 \%$ & $20 \%$ & $8 \%$ & $7 \%$ & $45 \%$ & $45 \%$ \\
\hline B & $26 \%$ & $13 \%$ & $20 \%$ & $23 \%$ & $19 \%$ & $22 \%$ & $43 \%$ & $43 \%$ \\
\hline C & $25 \%$ & $19 \%$ & $18 \%$ & $12 \%$ & $36 \%$ & $46 \%$ & $22 \%$ & $22 \%$ \\
\hline D & $23 \%$ & $15 \%$ & $17 \%$ & $19 \%$ & $21 \%$ & $18 \%$ & $48 \%$ & $48 \%$ \\
\hline
\end{tabular}

Source: Authors' own research

With the exception of company B, paid traffic doesn't exceed 30\% of the total traffic of the SMEs (Table 3). This is most likely due to the fact that advertising is essential in the retail 
sector in order to become and remain competitive. The large number of clothing e-commerce retailers makes it more difficult to attract organic traffic than in other less competitive and accessible fields. The advertising budget of Company A is also 57\% bigger than the one for Company B. However, Company B manages to generate more paid traffic due to its lower CPC rate (0.1 vs. 0.36 in 2018).

Table 4. Paid and organic traffic of the SMEs

\begin{tabular}{|c|c|c|c|c|c|}
\hline Company & Paid traffic & \%of total & Organic traffic & \%of total & Total \\
\hline A & 30556 & $25 \%$ & 90852 & $75 \%$ & $\mathbf{1 2 1 4 0 8}$ \\
\hline B & 70061 & $40 \%$ & 106923 & $60 \%$ & $\mathbf{1 7 6 9 8 4}$ \\
\hline C & 10638 & $29 \%$ & 26562 & $71 \%$ & $\mathbf{3 7 2 0 0}$ \\
\hline D & 30952 & $27 \%$ & 85620 & $73 \%$ & $\mathbf{1 1 6 5 7 2}$ \\
\hline
\end{tabular}

Source: Authors' own research

A series of interesting results derived from correlating the advertising budget with the total number of visitors on the online stores in the 4 trimesters of 2018. Figures 2, 3, 4 and 5 show a strong positive pattern between the two. All four SMEs have encountered more traffic - both organic and paid - when they increased their advertising budget and naturally, less when the budget was cut. Although this was predictable, the graphs show almost the exact same pattern in all cases, which validates a part of our $1^{\text {st }}$ hypothesis related to the very short-term impact of advertising on reach and traffic.

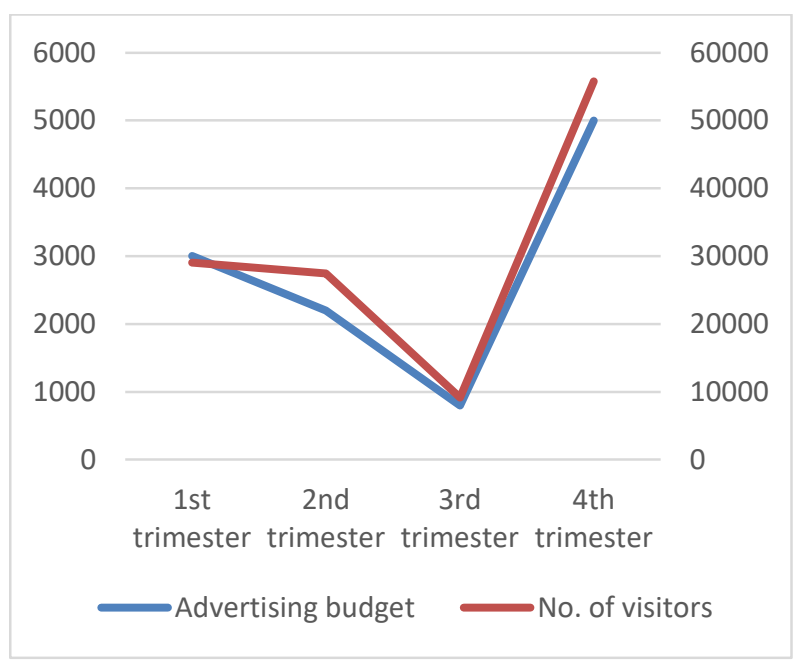

Figure 2. Company A

Source: Authors' own research

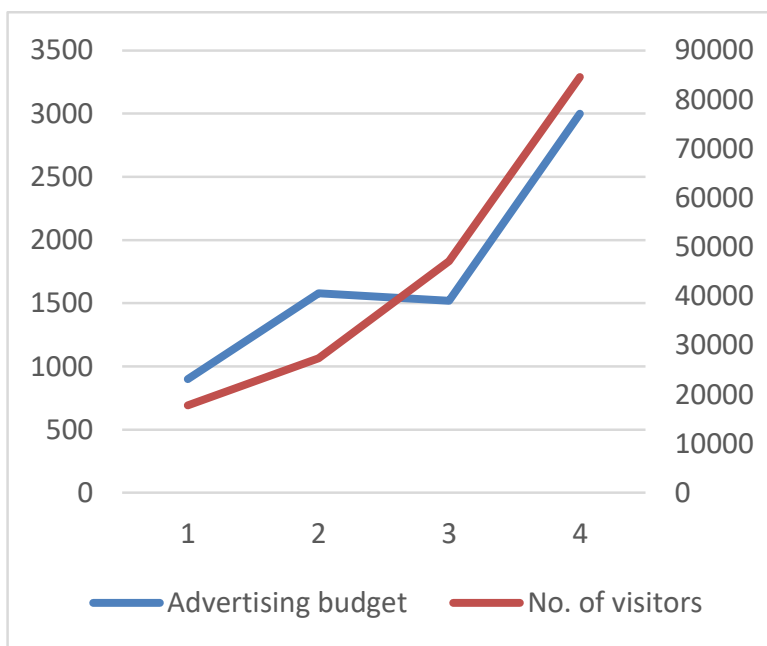

Figure 3. Company B

Source: Authors' own research 


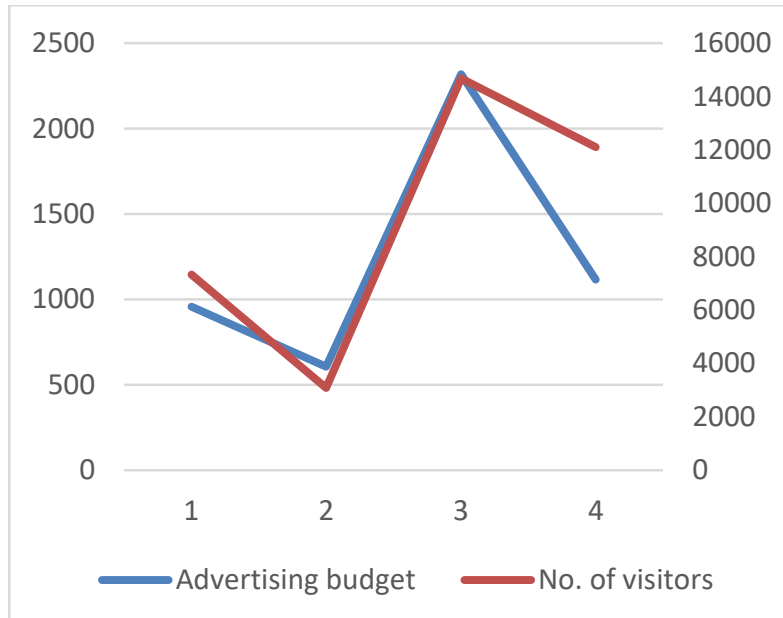

Figure 4. Company C

Source: Authors' own research

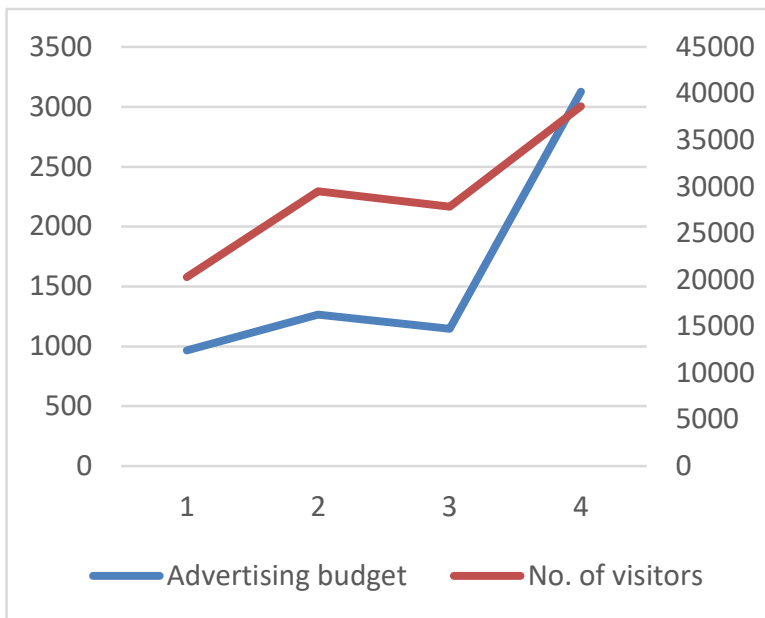

Figure 5. Company D

Source: Authors' own research

The next indicator we looked at was the sales conversion rate (Table 5). This is one of the most important outcomes of online advertising. If for companies A, C and D paid conversion is lower than the organic one, for company B we see the opposite result due to the same increased competition we have previously discussed. This means that a smaller percentage of people that access the website either directly or through organic search on both social media and search engines end up buying a product. The relatively high rate of organic conversion for Company $\mathrm{C}$ is related to the brand's specificity of food and the lack of identical substitutes on the market.

Table 5. Number of Customers and Average Conversion Rate for 2018

\begin{tabular}{|c|c|c|c|c|}
\hline \multirow{2}{*}{ Company } & \multicolumn{2}{|c|}{ No. of customers } & \multicolumn{2}{c|}{ Average Conversion Rate } \\
\cline { 2 - 5 } & Paid & Organic & Paid & Organic \\
\hline A & 1833 & 6360 & $6 \%$ & $7 \%$ \\
\hline B & 2100 & 2138 & $3 \%$ & $2 \%$ \\
\hline C & 957 & 3187 & $9 \%$ & $12 \%$ \\
\hline D & 2476 & 8562 & $8 \%$ & $10 \%$ \\
\hline
\end{tabular}

Source: Authors' own research

In order to determine the effectiveness of paid advertising for the 4 SMEs we analysed their returns on ad spending and returns on investment, considering the average value of shopping cart (AVSC) in relation to the average profit rate disclosed by the companies (Table 6). The high difference between the return on ad spending (RAS) and return on investment (ROI) is due to the measurement issue described in the methodology section. 
Table 6. Average value of shopping Cart (VSC), number of customers resulting from paid advertising (CPS), paid advertising driven sales (PADS), profit rate (II), return on ad spending (RAS) and return on investment (ROI)

\begin{tabular}{|c|r|c|c|c|c|c|}
\hline \multirow{2}{*}{ Company } & \multicolumn{1}{|c|}{ AVSC } & CPS & PADS & П & RAS & ROI \\
\hline A & $€ 20$ & 1833 & $€ 36,667$ & $18 \%$ & 0.60 & $168 \%$ \\
\hline B & $€ 52$ & 2100 & $€ 109,200$ & $31 \%$ & 4.84 & $876 \%$ \\
\hline C & $€ 10$ & 957 & $€ 9,574$ & $38 \%$ & 0.73 & $215 \%$ \\
\hline D & $€ 285$ & 2476 & $€ 705,714$ & $17 \%$ & 18.67 & $8224 \%$ \\
\hline
\end{tabular}

RAS seems to be under the 1:1 break-even point in the case of companies A and C. We have tried to understand the point of view of the companies' marketers since, in economic terms, the results are showing a loss. For Company A the marketer told our team that in their case, the Facebook campaigns convert to immediate traffic but not sales. For example, someone who sees an ad for a book might access the website to check the price and then come back directly to the website at a future date to make the purchase. This is similar to what happens in the case of Company $\mathrm{C}$ where the marketing officer mentioned that socialmedia advertising has the primary purpose of increasing awareness that will eventually lead to sales. With recent advances in tracking technologies it would likely be possible to implement better tracking mechanisms on the respective websites of these two companies in order to also measure conversions happening at a later date.

In the case of retail - Company B and home-improvement - Company D, conversions tend to happen immediately, RAS is much larger than 1 , and both companies tweak their advertising budgets based on conversions.

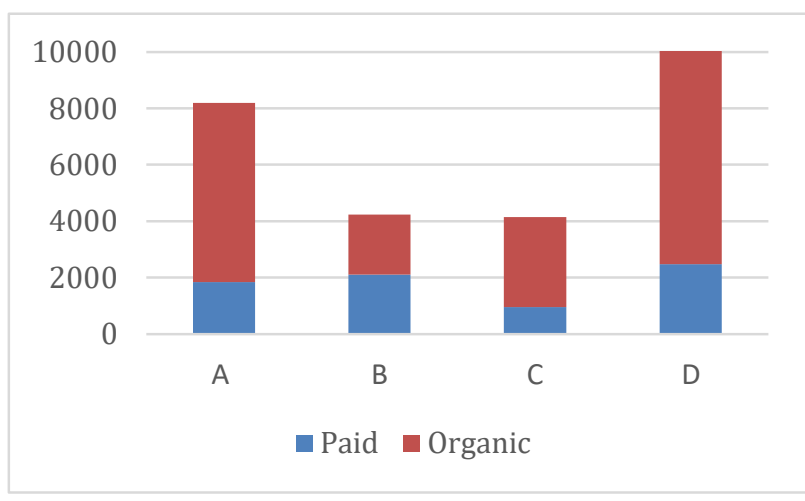

Fig. 6. Paid and organic sales 2017

Source: Authors' on research

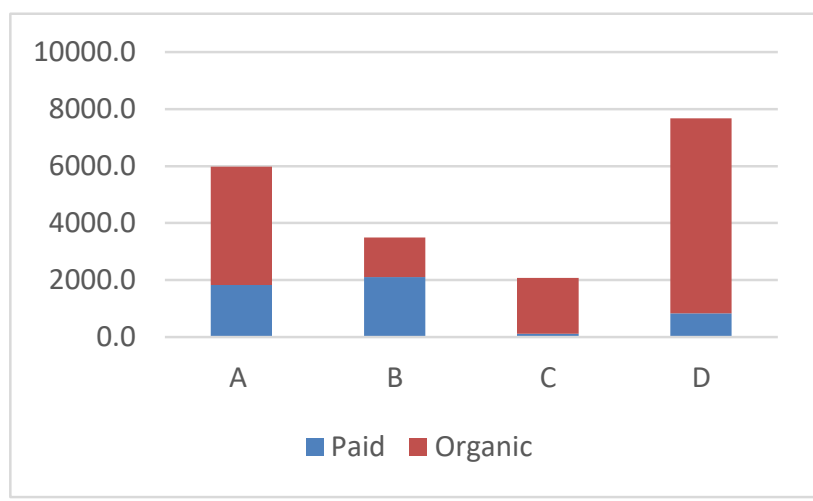

Fig. 7. Paid and organic sales 2018

Source: Authors' on research

We have performed a correlation test to determine if the increased budget of 2017 has had an effect on the organic sales of 2018. The results showed no correlation between the two, but rather a very strong correlation between the level of advertising budget and the organic sales in the same year (Figure 6 and 7). This validates Hypothesis 2 arguing that continuous advertising spending not only affects paid advertising driven sales but also organic sales due to the same phenomenon of delayed conversions described in the previous 
paragraphs. We have not noticed any difference in results between companies $\mathrm{B}, \mathrm{C}$ and $\mathrm{D}$ which are new and company A which has been in business since 1993, however, there are many plausible reasons and explanations for this lack of correlation, including the sample size, the impossibility to split the target audience into discernible units etc.

Lastly, we have analysed the number of repeat customers coming from advertising campaigns and the average life time value of these customers. Table 7 shows that a significant number of the customers that came to the websites through paid campaigns over a period of one year continue to make purchases from the same store. These results further validate $\mathrm{H} 2$.

Table 7. Number of repeat customers in 2018, their average lifetime value (LTV), and estimated average number of purchases per repeat customer (PPRC)

\begin{tabular}{|c|c|c|c|c|}
\hline Company & Customers & $\begin{array}{c}\text { \% of customers generated } \\
\text { through advertising }\end{array}$ & LTV & PPRC \\
\hline A & 352 & $19.2 \%$ & $€ 75$ & 3.8 \\
\hline B & 536 & $25.5 \%$ & $€ 164$ & 3.2 \\
\hline C & 301 & $31.4 \%$ & $€ 231$ & 23.1 \\
\hline D & 317 & $12.8 \%$ & $€ 383$ & 1.3 \\
\hline
\end{tabular}

Source: Authors' own research

It's worth noting that repeat customers are identified by all companies in our sample group because they use the same client account to place additional orders. One of the marketing officers we interviewed mentioned that it is entirely possible for some of their customers to order several times using different accounts which would make the number of repeat customers even larger. Better tracking and improved per client allocation of purchases should become possible in the near future as advanced tracking technologies are implemented.

The most interesting result by far was the extremely high number of repeat purchases coming from advertising generated customers for Company C, operating in the food industry. This information clearly validates the belief of their marketing officer that their low RAS of only 0.73 is offset by future orders. On the opposite, in the case of Company A, by assessing PPRC, the number of repeat customers, and their even lower RAS of 0.6 we can determine that the company comes close to covering their costs but their advertising spending is only justified if the brand awareness generated by the online advertising campaigns generates significand sales through other sales channels that were not covered by our study.

\section{Conclusion}

Our study aimed to assess the long-term effectiveness of paid advertising on sales and profit. We have used, as case studies, four representative Romanian SMEs, each active in a different industry. Our results show that social media marketing and search engine advertising have a strong positive impact on both paid and organic driven sales. By comparison to Blake, Nosko, \& Tadelis (2015)'s study, that shows how the efficacy of SEM is limited in the case of a big brand like eBay due to a concentration of ad spending on consumers that would shop on eBay regardless of seeing the ad or not, the results of our case studies show that a decreased advertising budget affects positively the number of visitors and the stores' sales. 
The paper proves the existence of an incremental value generated by ad campaigns. However, the results cannot necessarily be translated in immediate sales but they do convert to organic trafic. This would suggest that the return on investment for campaign ads should account for soft non-financial metrics (Heggestuen, 2013) like impressions, page views and brand awareness.

\section{Future Research}

As advertising channels start to diversify according to specific industries, research that broadens the understanding about customer targeting and returns could be worthwhile. Moreover, it would be interesting to develop an indicator that could better show conversions that do not happen immediately after the user clicks on the campaign ad. The effectiveness of paid advertising could also be studied at the level of SEM messages, following some already existing research (Goodrich, Schiller, \& Galetta, 35-50).

\section{Limitations}

Our results face certain limitation due to the size of the study's sample group. Although the companies which allowed us access to their data are representative for the average SME in their respective fields, the size of our sample puts some limitations on the extent to which the findings of this study can be generalised. As paaid advertising continues to increase, additional studies should look at longer time periods for a bigger sample group, provided enough companies willing to share this data can be identified.

\section{References}

Aswani, R., Kar, A. J., Ilavarasan, V., \& Dwivedi, Y. K. (2018). Search engine marketing is not all gold: Insights from Twitter and SEOClerks. International Journal of Information Management, 38(1), 107-116.

Blake, T., Nosko, C., \& Tadelis, S. (2015). Consumer Heterogenity and Paid Search Effctiveness: A Large-Scale Field Experiment. Econometrica, 83(1), 155-174.

Brettel, M., Reich, J. C., Gavilanes, J. M., \& Flatten, T. C. (2015). What Drives Advertising Success on Facebook? An Advertising-Effectiveness Model. An AdvertisingEffectiveness Model. Meauring the Effects on Sales of "Likes" and Other SocialNetwork Stimuli. Journal of Advertising Research, 162-175.

Buhalis, D., \& Mamalakis, E. (2015). Social Media Return of Investment and Performance Evaluation in the Hotel INdustry Context. In I. Tussyadiah, \& A. Invesrsini, Information and Communication Technologies in Tourism (pp. 241-253). Springer International Publishing.

De Corniere, A. (2016). Search Advertising. American Economic Journal: Microeconomics, $8(3), 156-188$.

eMarketer. (2013, 02 25). Advertisers boost social ad budgets. Retrieved from https://www.emarketer.com/Article/Advertisers-Boost-Social-Ad-Budgets$2013 / 1009688$

Goldfarb, A. (2014). What Is Different About Online Advertising:? Review of Industrial Organization, 44(2), 115-129. 
Goodrich, K., Schiller, Z., \& Galetta, D. (35-50). Consumer Reactions to Intrusiveness of Online-Video Advertisements. Do Length, Informativeness, and Humor Help (or Hinder) Marketing Outcomes? Journal of Advertising Research, 55(1), 2015.

Heggestuen, J. $(2013,1022)$. The death of social ROI - Companies are starting to drop the idea that they. Retrieved from Business Insider:

https://www.businessinsider.com/the-myth-of-social-roi-2013-10

PICBE |

Hudák, M., Kianičková, E., \& Madleňák, R. (2017). The Importance of E-mail Marketing in E- 1191 commerce. Procedia Engineering, 192, 342-347.

Lee, D., Hosanagar, K., \& Nair, H. S. (2018). Social Media: Evidence from Facebook. Management Science. Articles in Advance, 1-27.

Peng, J., \& Van den Bulte, C. (201, 01 15). Participation vs. Effectiveness of Paid Endorsers in Social Advertising Campaigns: A Field Experiment. doi:https://dx.doi.org/10.2139/ssrn.2702053

Pooja, M., Black, E., Jingmei, C., Berger, P. D., \& Weinberg, B. D. (2012). The Impact of Social Media Usage on Consumer buying Behvior. Advances in Management, 5(1), 14-22.

PricewaterhouseCoopers. (2017). IAB internet advertising revenue report. New York, USA. Retrieved 02 10, 2019, from https://www.iab.com/wpcontent/uploads/2016/04/IAB_Internet_Advertising_Revenue_Report_FY_2016.pdf

Statista. (2019). Online advertising metrics - Statistics \& Facts. Retrieved 01 20, 2019, from https://www.statista.com/topics/5063/online-advertising-metrics/

Suciu, M., Kolodziejak, A., Năsulea, C., Năsulea, D., \& Postma, E. (2018). The Impact of Big Data on Knowledge Management Systems in Romanian E-commerce Retailers. European Conference on Knowledge Management (pp. 821-828). Padova: Academic Conferences and Publishing International.

Taylor, D. G., Lewin, J. E., \& Strutton, D. (2011). Friends, Fans, and Followers: Do Ads Work on Social Networks? How gender and Age Shape Receptivity. Journal of Advertising Research, 51(1), 258-275.

Tucker, C. (2012). Social Advertisign. Working Paper. doi:10.2139/

Vakratsas, D., \& Ambler, T. (1999). How Advertising Works: What do We Really Know? Journal of Marketing, 63(1), 26-43.

Yang, S. L., \& Shan. (2016). Brand engagement on social media: will firms' social media efforts influence search engine advertising effectiveness? Journal of Marketing Management, 32, 526-557.

Yang, Z., Shi, Y., \& Wang, B. (2015). Search Engine Marketing, Financing Ability and Firm Performance in E-commerce. Procedia Computer Science, 55, 1106-1112. 